\title{
Dissecting Heart Failure Through the Multiscale Approach of Systems Medicine
}

\author{
Linda Pattini*, Roberto Sassi, Senior Member, IEEE, and Sergio Cerutti, Fellow, IEEE
}

\begin{abstract}
Heart failure (HF) is a complex syndrome which can be the exit of different etiologies which lead to a common clinical picture. Treatment outcome is modest and new insights into pathophysiology are needed to improve effectively diagnosis, prognosis, and therapy. As a complex disease, it can really benefit from the new approach provided by molecular medicine where information about the cell program can deeply change the patient management. The comprehension of molecular mechanisms relies on new technologies which are able to provide data at the different levels of the cell workflow. A proper processing of these data is as essential as the generation of data itself, together with an integrative approach able to exploit observations at different scales, starting from the molecular levels up to an effective assessment of phenotype with cardiovascular and systemic parameters. In this paper, evidences concerning current understanding of $\mathrm{HF}$, passing from one scale to another, are reported, to underline how functional genomics and systems biology perspective, fostered by the combination of biotechnologies and bioinformatic methods, may transform the concepts of diagnosis and, consequently, of treatment, toward the fulfillment of the invoked patient-specific medicine.
\end{abstract}

Index Terms-Bioinformatics, biomedical signal processing, functional genomics, heart failure (HF), multiscale data analysis.

\section{INTRODUCTION}

$\mathbf{H}$ EART failure (HF) is a complex syndrome consisting in the inability of the heart to provide adequate blood flow to meet the body's metabolic needs, leading to clinical manifestations such as fatigue, breath shortness, diminished exercise capacity, fluid retention.

In the U.S. more than 500000 new HF cases are diagnosed annually and lead approximately to 50000 deaths per year. In the western world, the prevalence of HF can be estimated at $1 \%-2 \%$ and, as concerns the cardiovascular field, it represents the second most common diagnosis after hypertension [1], [2]. Moreover, with the greater longevity, prevalence, and incidence are likely to increase.

Many different etiologies can lead to the onset of this syndrome which culminates in a common general clinical picture.

Manuscript received November 20, 2013; revised February 4, 2014; accepted February 8, 2014. Date of publication February 24, 2014; date of current version April 17, 2014. Asterisk indicates corresponding author.

${ }^{*}$ L. Pattini is with the Department of Electronics, Information and Bioengineering, Politecnico di Milano, Milan 20133, Italy (e-mail: linda.pattini@ polimi.it).

R. Sassi is with the Department of Computer Science, Università degli Studi di Milano, Crema 26013, Italy (e-mail: roberto.sassi@unimi.it).

S. Cerutti is with the Department of Electronics, Information and Bioengineering, Politecnico di Milano, Milan 20133, Italy (e-mail: sergio.cerutti@ polimi.it).

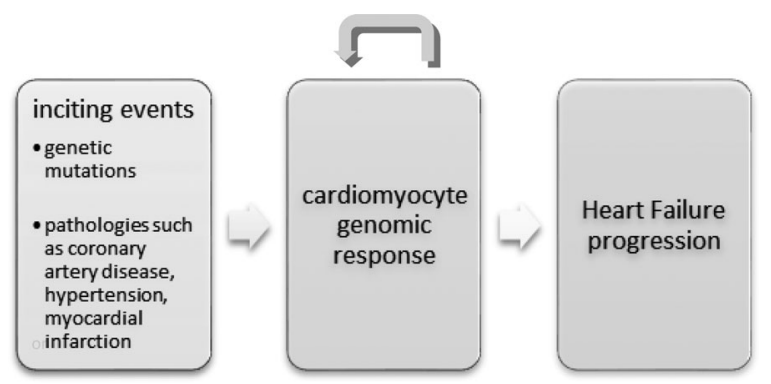

Fig. 1. Single gene mutations or cardiovascular diseases can trigger a transcriptional reprogramming of cardiomyocytes which, although compensative, will lead to HF progression, from the asymptomatic stage to clinical manifestations.

The essential cause of HF is attributed to a loss of function of cardiomyocytes which reply to some stress and/or exceptional loading by reprogramming their gene expression, especially as concerns genes involved in metabolism, ions handling, and the reuse of genes which are specific of the fetal development [3]. This physiological response may trigger a positive feedback, overloading the cardiomyocytes leading eventually to cardiac dysfunction, as outlined in Fig. 1. At the early stages of disease progression, functional capacity of the patient is preserved through compensatory neurohormonal mechanisms as the activation of the adrenergic nervous system, of the reninangiotensin-aldosterone system, the nonosmotic release of arginine vasopressin, the secretion of natriuretic peptides, endothelial hormones, nitric oxide, and cytokines [4], [5]. As a consequence, the myocardium develops hypertrophy and interstitial fibrosis [6] due to alterations of the extracellular matrix, undergoing a remodeling process. The long-term activation of these compensatory mechanisms, which initially are able to preserve hemodynamic homeostasis, lead progressively to cardiac dilation and decrease of contractility till the "decompensated" stage and the precipitation of HF symptoms.

Although the "neurohormonal model" can depict a convincing explanation of disease progression, a more detailed scenario of the molecular landscape underlying $\mathrm{HF}$ is required to improve the current therapeutic strategies.

The advent of molecular medicine can shed light on the fundamental mechanisms which lead to HF, exploiting the information at the cellular level to understand the underlying mechanisms of cardiomyopathy [7], [8], transforming the concepts of diagnosis and, consequently, of treatment, toward the so-called personalized medicine. Indeed, the genomics and systems biology perspective fed by data produced by the new technologies together with the development of adequate computational approaches, may provide new insights into HF pathophysiology leading to new and more specific therapeutics. 
TABLE I

GENES LINKED TO INHERITED FORMS OF HEART FAILURE

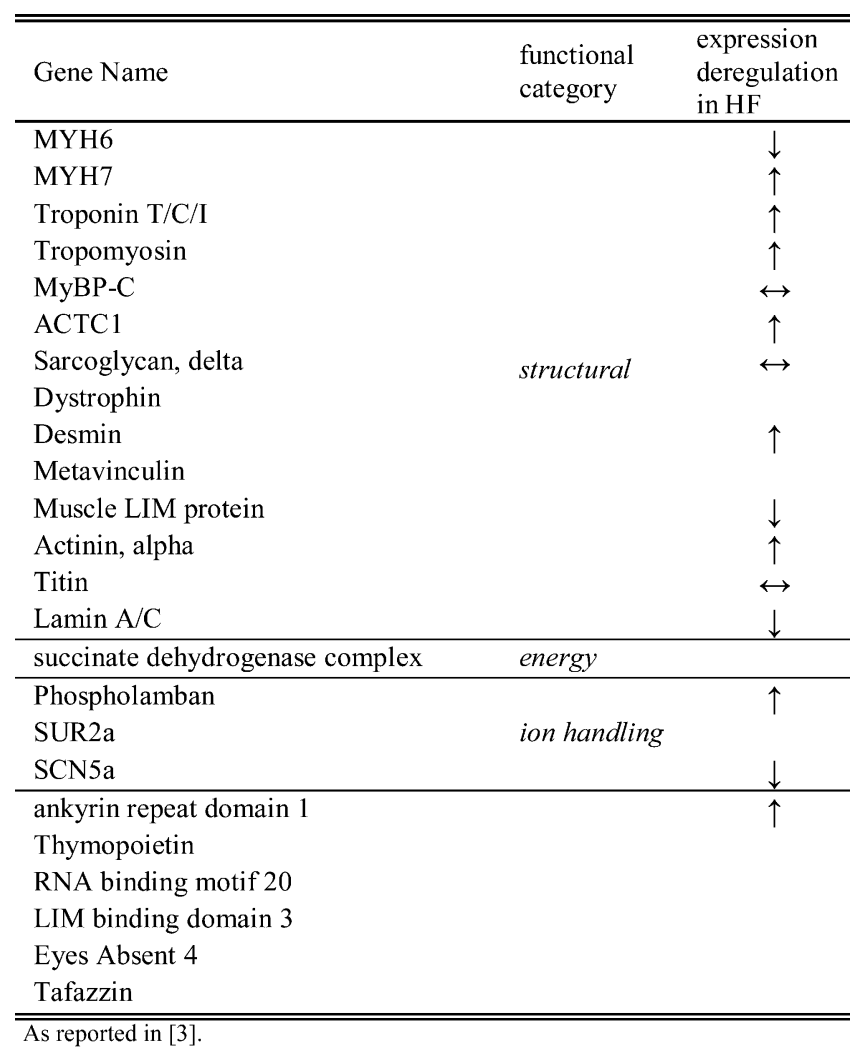

\section{Genetics And Functional Genomics}

\section{A. Inherited Forms of $\mathrm{HF}$}

Traditionally, genetic forms of $\mathrm{HF}$ are distinguished from the so-called acquired forms. The former category encompasses familial dilated cardiomyopathy (DCM), hypertrophic cardiomyopathy and arrhythmogenic right ventricular cardiomyopathy. Genes whose mutations (see Table I) can cause these inherited forms were found mainly by means of linkage analysis or candidate gene association studies on neurohormonal pathways and encode proteins that have a role in generation and transmission of contractile force (sarcomere proteins, cytoskeletal proteins, desmosome proteins, lamin A/C protein, whose mutations are the most frequent in DCM patients (with a percentage of 7.3\%), energy production (mitochondrial proteins), calcium handling, transcription regulation [9].

However, it was observed that mutations in the same genes can lead to different forms of familial cardiomyopathy [10], [11], demonstrating that single mutations may be not specific and completely explanatory of the phenotype and a more complex portrait is needed to characterize the triggered molecular response.

\section{B. Transcriptomics}

What is apparent at a clinical level in the disease progression (with signs as myocardium hypertrophy and interstitial fibrosis) is actually the outcome of a reprogramming of gene expression, which represents the physiological response of myocytes to stress conditions. So, a detailed analysis of the transcriptome becomes of paramount importance to study and characterize the myocardial tissue at the molecular level, unveiling genes and pathways which are perturbed in inherited and acquired forms of disease [12].

Starting from the beginning of the new century, gene expression studies have been presented aimed at the characterization of HF dysregulome [13], [14]. Tan et al. [15] compared oligonucleotide microarrays-based profiles of eight failing (tissue extracted from the left-ventricle of explanted hearts of transplant recipients) and seven nonfailing (organ donors) human hearts. The analysis allowed to identify a signature of differentially expressed genes in HF where atrial natriuretic factor and brain natriuretic peptide (BNP) were the most up-regulated genes, consistently with the known biomarkers. And consistently with the known myocytes reversal to a fetal program, $\alpha$-actin was found down-regulated whereas myosin heavy chain- $\beta$ was found up-regulated. Due to the remodeling process, deregulation of genes encoding extra-cellular matrix and cytoskeleton proteins, involving fibromudulin, t-plastin, fibronectin and desmosome-associated, was reported together with a significant increase of collagen types I and III responsible for myocardial tissue stiffness and deterioration. Moreover, genes involved in proteolysis and stress response, as thrombospondin-4, were found up-regulated. Genes belonging to metabolism pathways were differentially expressed, showing an overall downregulation attributable to fatty acid metabolism and an overexpression of genes involved in glucose metabolism. Consistently with the known loss of cardiomyocytes in HF, a downregulation of antiapoptotic genes emerged. Up-regulation of two ligands of the transforming growth factor (TGF)- $\beta 1$ was found significant; it is, indeed, considered a crucial regulator of remodeling [6]; overexpression of TGF- $\beta 1$ in transgenic mice was shown to be causative of interstitial fibrosis and myocytes hypertrophy.

Along with confirmations of known findings, gene expression profiling improved the characterization of the genetic pathways involved in the physiopathology, at least as the used experimental platform, which is now obsolete, allowed. Unsupervised clustering techniques, specifically $k$-means algorithm, was used to group gene expression profiles across the samples, based on the assumption that genes that appear to be coregulated may contribute to the same process and unveil novel relationships; this allowed to override the univariate differential analysis and group genes combining functional annotations and expression patterns.

A hierarchical clustering algorithm was also applied to profiles across both the clinical samples and the genes identified as significant in differential analysis, obtaining the reorganized heatmap reported in Fig. 2, where healthy and pathological samples are correctly discriminated, confirming the informativeness of the signature identified. Interestingly, the samples F3 and F5 which segregate away from the other pathological samples have a different etiology: F5 was an inheritable form of HF and F3 cardiomyopathy was due to alcoholism.

Several studies on HF have been proposed based on gene expression data of heart tissue but, due to obvious limitations, 


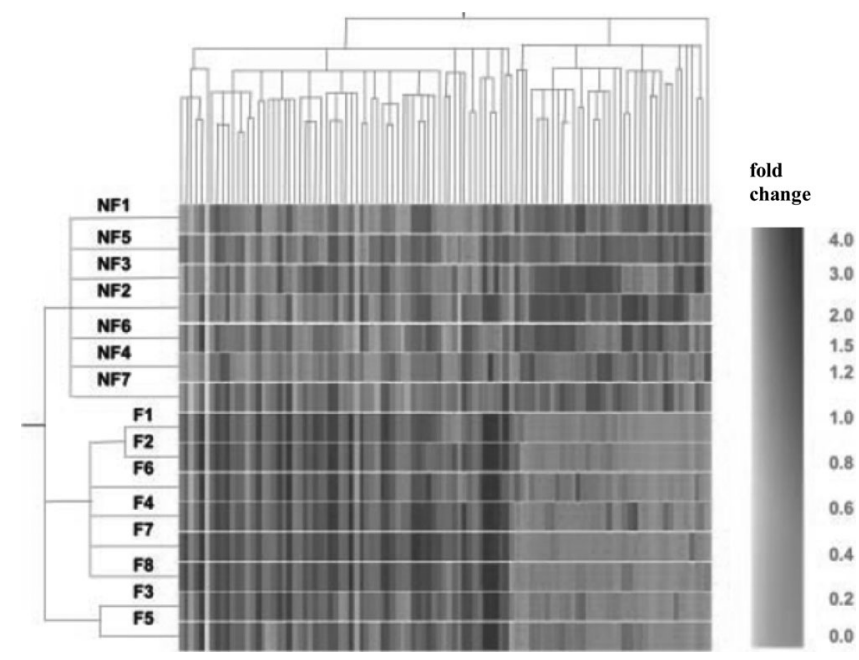

Fig. 2. Gene expression profiles of nonfailing (NF) and failing (F) heart tissue samples of the 103 differentially expressed genes identified. The color bar indicates fold change [from Tan et al., 2000, OPNAS].

murine models are widely used to characterize the physiopathology in terms of gene expression and regulation [16], [17]. Efforts toward the integration of gene expression profiles with phenotypic information at the system level have been shown, for example, with the identification of HF-associated genes correlated with clinical parameters such as pulmonary artery pressure and ejection fraction [18]. As said, myocardial gene expression studies are very important to unveil the pathophysiology mechanisms; on the other hand, for a disorder like HF, whose nature is obviously systemic, peripheral blood transcriptomics can provide important information, which can be applied at different levels of patient management, from diagnosis, to prognosis, monitoring, and treatment personalization. Van Buren et al. have recently identified a peripheral blood gene expression signature significantly associated with outcomes in HF patients [19].

Still in peripheral blood, a signature of seven genes was recognized as a predictor of early stage (asymptomatic) HF, which can be diagnosed only by echocardiography; such a result may represent a useful tool for large screening of population at risk [20].

Large-scale gene expression experiments are generally accomplished on samples representing a population of cells. Current approaches in transcriptomics (microarrays or RNA-seq) rely on measurements of RNA molecules pooled from a large number of cells. However, individual cells may exhibit a considerable heterogeneity in the expression of genes and their protein products. Monitoring molecular abundances of many distinct cells can unveil diversity of cell states and circuits and inherent stochastic variation, improving our comprehension of functional genomics both in physiology and in pathophysiology [21]. The acquisition of single cell spatial-temporal patterns has a great potential for data analytics and modeling and offers great challenges on the technological side for developing efficient experimental platforms along with adequate low-level data processing [22]-[24].

\section{Genetics versus Genomics}

Moving from genetics, with the analysis of the genomic sequences interindividual variability, to transcriptomics adds a powerful layer of information. Processing expression data shows that different initial events (as hypertension, myocardial infarction, coronary artery disease, single gene mutations) can lead to a common response in terms of cell program and, at the same time, can allow the identification of specific signatures able to discriminate HF subtypes which would be indistinguishable at the clinical level. Addressing the inherent heterogeneity of a complex syndrome such as HF by means of molecular profiling is an important challenge in molecular medicine. This approach, for example, has already proven to be successful and is currently widely applied in cancer genomics.

The study of the genomic program, with the characterization of what the cell is really expressing and with the specification of the molecular determinants involved in the disease progression, is essential to reach a deep comprehension of the HF pathophysiology, allowing new target discovery and etiological (and consequently therapeutic) subtypes identification.

Looking at sporadic HF as a complex disease, it can be worth studying the contribution of genetic risk factors which can modulate the risk of developing acquired HF [25]. Modern high throughput technologies (genomewide SNP detection and deep sequencing platforms) allow to genotype subjects very efficiently providing the data to derive associations between alleles and pathology at a genome-wide level. In this direction, some studies have been presented. However, it can be observed that many of these associations have not been replicated and the ORs are rather low [26]. Moreover, sometimes the mutation identified belongs to a genomic position which is not clearly characterized from a functional point of view.

However, even if these mutations do not cause disease, they may modulate HF risk (see Fig. 3), progression and therapeutics responsiveness. Moreover, their identification can pinpoint the different functional elements of the genome which are involved in the myocardial response to overload, influencing the balance between a compensatory response and a progressive limitation of cardiac function.

Actually, genetic forms of HF, where single gene mutations are able to trigger the development of the disease, and acquired forms of HF (due, for example, to hypertension, myocardial infarction, etc.) lead to the same cardiac response whose fate and severity can be modulated by individual variability in genomic sequences.

It is interesting to note that many genes whose mutations are known causes of HF do not show deregulated expression levels in failing hearts. This contraposition between genetics and genomics might be solved hypothesizing that some genetic factors may trigger the overload of the myocardium, whose response determines changes in the expression of different genes. In this more comprehensive perspective, even the classification in inherited and acquired forms could be overcome.

This has been already observed discussing the general lack of overlap between genes harboring mutations and dysregulated genes and its possible explanation in the gene network context, 


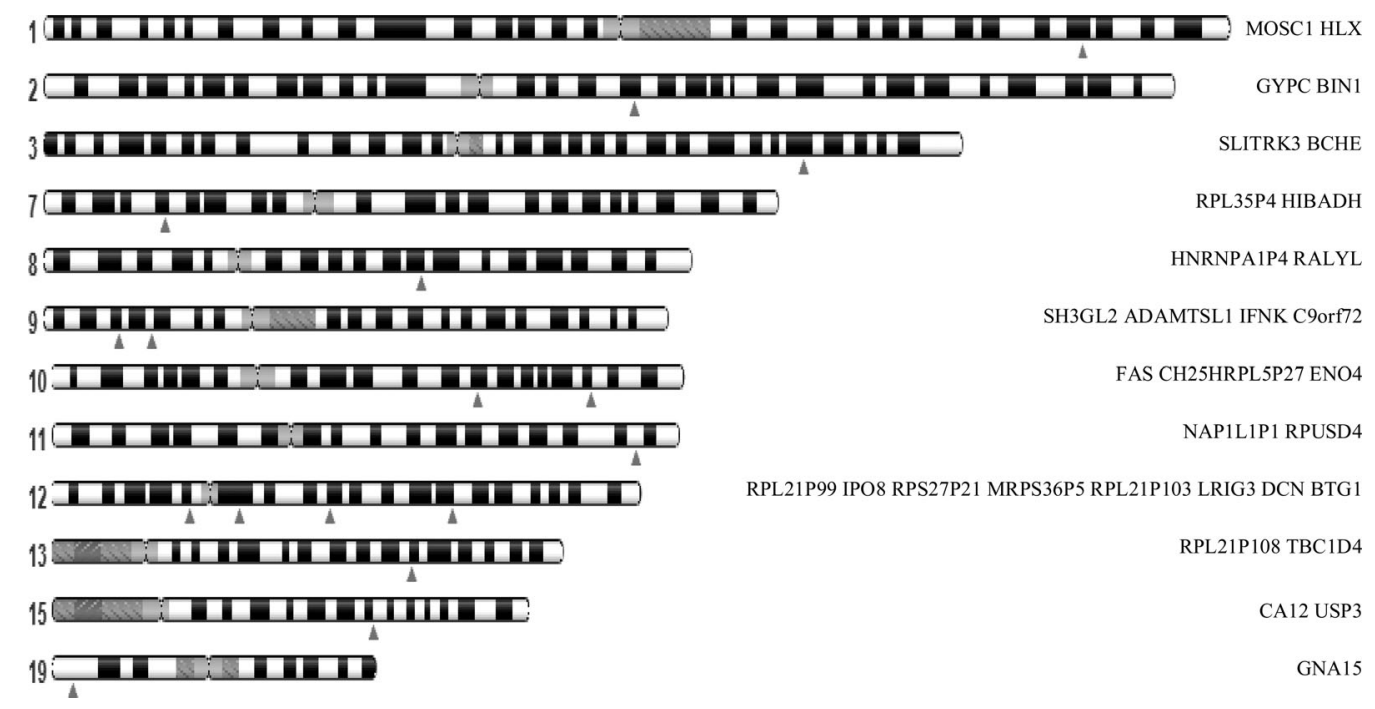

Fig. 3. Genomic position and gene region of variants which have been associated with the risk of incident heart failure [65], visualized through NCBI dbGaP Data browser (NHGRI source).

arguing that mutated genes may be considered as upstream determinants while genes, whose expression is altered, are in general downstream effectors in the economy of the perturbed pathway.

\section{Opportunities for Gene Expression Regulation}

As seen, the elicitation of the functional elements of the genomic cell program and their mutual interactions in a systems biology perspective is indispensable. New technologies along with adequate bioinformatic approaches are essential and may help in redefining [27] HF in the postgenomic era. The study of the genome along with progresses in transcriptomics revealed that only a small portion of it is transcribed into protein coding mRNAs in vertebrates. However, the human transcriptome involves almost the $90 \%$ of the genome due to many different types of noncoding RNAs, whose classification is still unclear. Thus, complexity of higher organisms must be searched for not in the limited number of protein coding genes (about 22000 for humans, but more than 20000 also for the nematode Caenorhabditis Elegans) but rather in their fine regulation in time and space (different tissues) which noncoding RNAs and mechanisms of transcript processing (alternative splicing) contribute to.

1) MicroRNAs (miRNAs): miRNAs are important gene expression regulatory elements and as such their role in the pathogenesis and progression of cardiac disease and HF has been recently emerging [28]. MiRNAs are small noncoding RNAs (about 22 nucleotides in length) that inhibit expression of target genes by sequence-specific binding to the $3^{\prime}$ untranslated region of messenger RNA, determining its degradation or translational repression. MiRNA genes may be intergenic or intronic and are generally subject to the same transcriptional regulation of protein coding genes. Their transcripts (pri-miRNAs) are processed and folded in a 70-100 nucleotides long hairpin precursor (pre-miRNA), which is then exported to the cytoplasm and cut to obtain two separate strands: the mature miRNA and its complementary version which is often nonfunctional and led to degradation. The nucleotides $2-8$ at the $5^{\prime}$ end of the mature
miRNAs are referred to as "seed," as this portion of the sequence is fundamental in target recognition (an example is reported in Fig. 4). More than 2000 miRNAs are currently known in the human genome (as shown in the public dedicated repository miRBase) and are estimated to regulate more than half of protein coding genes. It is worth underlying that one transcript may contain binding sites for different miRNAs which act in combination and one single miRNA may target hundreds of genes influencing entire pathways.

The modulation of gene expression accomplished by miRNAs has been revealed as fundamental in cell development and tissue specification, indeed most targets belong to genes involved in cell-specific processes and, conversely, housekeeping genes are less subject to miRNAs action.

Differential expression of miRNAs can result in the consequent altered expression of direct (or indirect) targets, but it has also been suggested that they can exert a "buffering" function limiting excessive fluctuations of their targets (and conferring robustness to the cellular program) thanks to ad hoc positions in the gene circuitry.

Also the functional characterization of miRNAs within the human genome requires the development and the application of adequate bioinformatic approaches. The comprehension of the rules for miRNA-directed targeting of mRNAs relies on sequence analysis accomplished through pattern recognition methods, comparative genomics to identify phylogenetically conserved sites, structural accessibility analysis of the mRNA molecule, but also on gene expression data integration and systems biology approaches to study interactions on small and large scale. The development of target prediction strategies is still a major challenge in bioinformatics and computational genomics. Current predictors have a low level of accuracy and show a limited overlap in their results.

So far, many miRNAs (and many of their potential targets), which are involved in cardiac disease and HF development have been identified [28]. Experimental evidence of miRNA dysregulation was provided in relation to the different pathological 


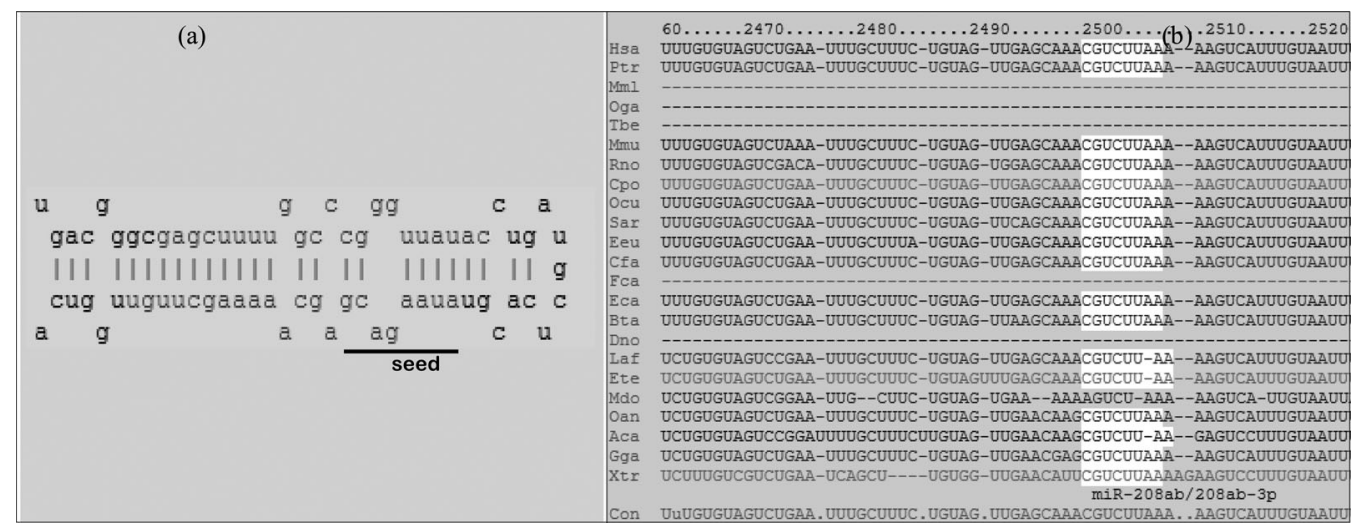

Fig. 4. (a) Secondary structure of the miRNA-208 a precursor (as retrievable from the miRBase database) is reported as an example; the typical hairpin structure is depicted, its processing leads to the formation of the mature form of the miRNA which is single strand; the seed is evidenced; (b) gene targets have a binding site in their transcript, typically in the $3^{\prime} \mathrm{UTR}$, which permits the binding through (partial and nonexact) sequence complementarity; the binding site is often phylogenetically conserved, as shown for the gene CHD9, predicted target of miR-208 a, for which a multialignment across different species is reported.

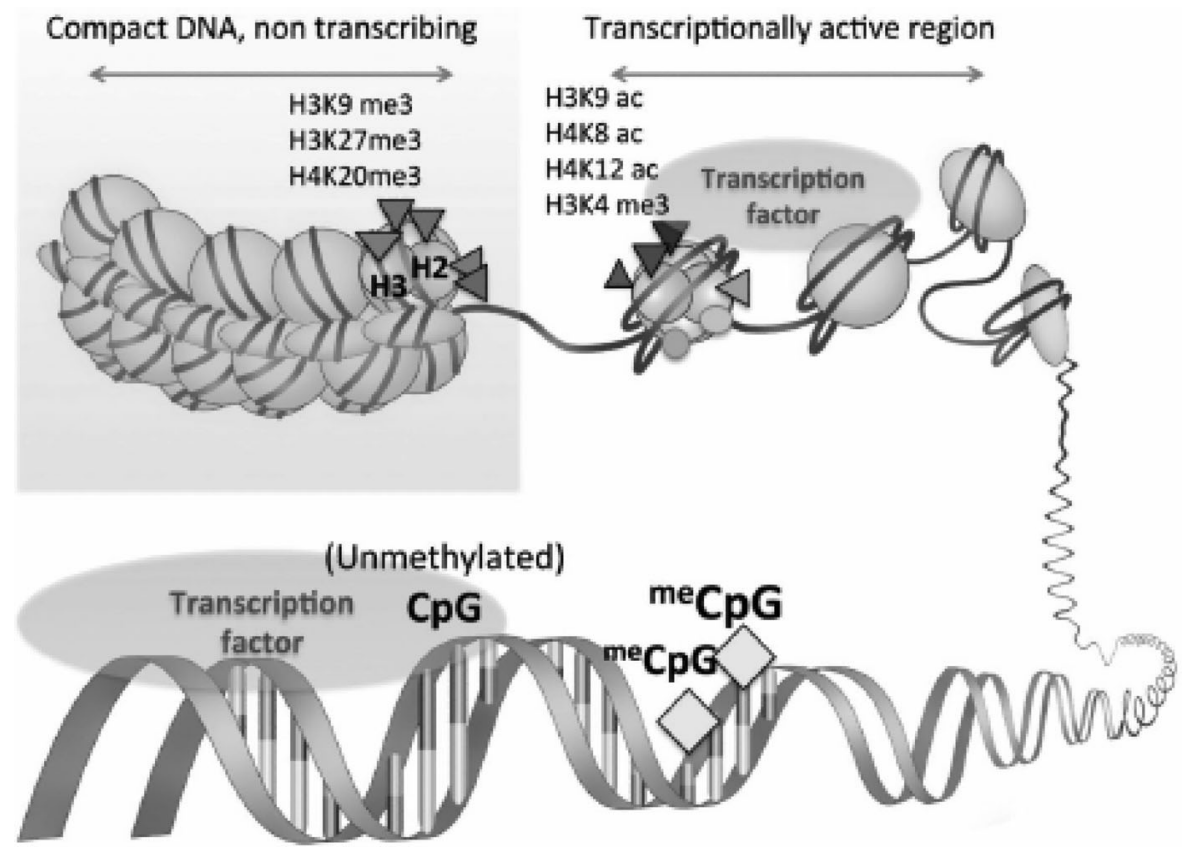

Fig. 5. Epigenetic modifications of DNA influence gene expression. DNA methylation: methylated cytosines in CG dinucleotides correspond to regions which are associated to transcriptional repression. Histone modifications (as methylation, acetylation, phosphorylation, etc.) can affect gene transcription; exemplificative schemas for condensed or relaxed, transcriptionally active DNA regions [from Baccarelli et al. 2012, reprinted with permission of Curr Opin Clin Nutr Metab Care].

processes characterizing HF, such as hypertrophy, fibrosis, remodeling, calcium handling changes.

For example, the first study reporting on miRNA expression showed that the overexpression of a combination of miRNAs upregulated in two murine models of $\mathrm{HF}$ was sufficient to induce hypertrophy in cardiomyocytes [29].

MiR-208 represents another interesting example, it is expressed exclusively in cardiac tissue and its silencing in MiR-208 knock-out mice resulted in a protective effect against pressure overload-induced hypertrophy and, conversely, cardiac specific overexpression of miR-208 determined a hypertrophic response. Successively, the therapeutic silencing of miR-208 a via subcutaneous delivery of a specific oligomer able to establish specific binding was shown to be effective in rats, preventing remodeling and myocyte functional degeneration [30]. This is an important result showing the potential of miRNAs as novel therapeutic targets for heart.

MiRNAs are present not only in the cytoplasm but also outside cells, in body fluids. The expression of miRNAs circulating in plasma, whose presence was demonstrated in a seminal paper by Mitchell et al. [31], has been emerging as a potential source of biomarkers for cardiovascular disease [32], [33]. Indeed, they are likely to reflect cell activation and tissue injury and, intriguingly, they could contribute to intercell signaling through a selective release into the systemic circulation, but origin and function remains poorly understood. They are known 
to be shed into the extracellular environment in microvesicles (exosomes, microparticles, apoptotic bodies), but the existence of plasma miRNAs in the fraction devoid of microvesicles was demonstrated and explored in several studies. In very recent cardiovascular research, circulating miRNAs have been investigated to gain insights into pathological mechanisms of many diseases as myocardial injury, coronary artery disease, diabetes, and hypertension. As concerns HF, for example, the expression of miR-423-5p [34] was found overexpressed in plasma of patients compared to controls subjects; and, successively, Goren et al. [35] showed that the expression level of a combination of four serum miRNAs could discriminate HF patients compared with healthy subjects. This signature, consisting of upregulated miRNAs with high statistical significance, even if with limited fold change, was shown to correlate with clinical parameters as serum BNP levels and QRS complex width, highlighting a multiscale crosstalk.

2) Long ncRNAs: Among the noncoding RNAs, a novel class of transcripts has been recently emerging for its potential in gene expression regulation: long noncoding RNAs (lncRNAs), whose length is greater than 200 nucleotides, are able to interfere with gene expression through various mechanisms, which still remain largely unknown, at pre- and posttranscriptional level.

The recent transcriptomics studies, thanks to microarrays and especially to next generation sequencing technologies, revealed that IncRNAs are modulated during development and have a key role in cell fate specification. Given their importance in gene transcription program, lncRNAs may play a role in pathophysiology of cardiac disease and specifically in HF [36]. The lncRNA Braveheart, for example, was shown very recently to be essential for cardiovascular lineage commitment [37] and it was found downregulated in plasma of mice in which $\mathrm{HF}$ had been induced by isoproterenol infusion. This animal model, which reproduces the cardiotoxic effects of chronic activation of the sympathetic system, was used, indeed, in a recent transcriptome analysis that showed also a unique pattern of circulatory lncRNAs. Specifically, dysregulated lncRNAs in plasma or whole blood were almost double than in heart tissue; moreover, the expression of lncRNAs in heart, whole blood and normal plasma was anticorrelated with transcript length, as expected, whereas this did not hold in HF plasma [38]. These results are suggestive of a potential role of circulatory lncRNAs, as for circulatory miRNAs, in pathogenesis, development and prognosis in HF. Then, a different murine model where pressure overload was surgically (through transaortic constrinction) provoked to induce hypertrophy and subsequently HF, showed the dysregulation of 15 heart tissue lncRNAs [17]. Another intriguing example of 1 cRNAs action is represented also by the transcript of the gene Kcnq1, which encodes a potassium channel subunit: an lncRNA is contained in one intron able to modulate the expression of the host gene, as demonstrated by Korostowski et al. [39].

3) Epigenomics: Opportunities of regulation are carried out by the cell also at the level of DNA structural organization. DNA of eukaryotic cells, indeed, is highly condensed in the nucleus to arrange the entire genome sequence. DNA wraps around nucleosomes, complexes of eight histone proteins, as a wire around bobbins. This combination of DNA and proteins, known as chromatin, can exhibit modulated condensation levels: briefly, an open chromatin structure (euchromatin) corresponds to a genomic region which contains expressed genes, whereas a tightly packed conformation (heterochromatin) corresponds to a genomic region which is transcriptionally inactive since it is not exposed to the transcription factors (see Fig. 5).

DNA methylation at $\mathrm{CpG}$ dinucletotides and histone modifications are processes that influence the DNA structure and, notably, they are also signals which can be acquired, thanks to the new technologies, and processed to add a dimension to the molecular profiling of regulatory mechanisms. These kind of heritable phenomena which act on the genome, altering the packaging but not the sequence, are referred to as epigenomics. Recent studies show that epigenetic mechanisms may play a role in cardiac hypertrophy and failure. For example, Movassagh et al. showed in their recent papers the existence of specific patterns of DNA methylation in human HF which correlate with the expression of genes involved in angiogenesis as PECAM1, ARHGAP24, and AMOTL2 [40] and also found a significant difference of trimethylation of lysine 36 in histone 3 in end-stage HF compared to control subjects [41].

It has been demonstrated also that hypertrophy can be induced by histone acetyltransferase activity that causes the overexpression of the transcription factor CREB and that it is influenced also by the interference of hyston acetylation with sarcomeric genes [42].

Very recently, two genes with differential DNA methylation patterns between DCM patients and controls were identified. They have been studied through silencing of their orthologous in zebrafish; this led to a reduced ventricular contractility and subsequent HF, validating the functional role of these genes in the disease development [43].

\section{PROTEOMICS AND METABOLOMICS}

If functional genomics delineates the cell program fascinatingly and powerfully going to the upstream phenotype determinants, proteomics technologies must be applied to assess the actual presence and the abundance of the gene products. They allow to cope with the further level of complexity represented by the proteome where co- and post-translational modification events amplify dramatically the number of proteins compared to the number of genes. Many studies concerning cardiac proteomics have been carried out using 2-D gel-based approaches (2-DE) in which proteins are separated along two orthogonal dimensions according to charge and to relative molecular mass and spots of interest are identified by means of mass spectrometry (MS). These 2-D maps need dedicated software for low-level quantification, differential analysis and classification approaches [44]. Due to several limitations in terms of sensitivity and dynamics, gel-free, MS-based proteomics, with its different platforms, has become widely applied. Peptides obtained through sample digestion are separated according to the $\mathrm{m} / \mathrm{z}$ ratio producing spectra (single-stage spectra for the so-called 


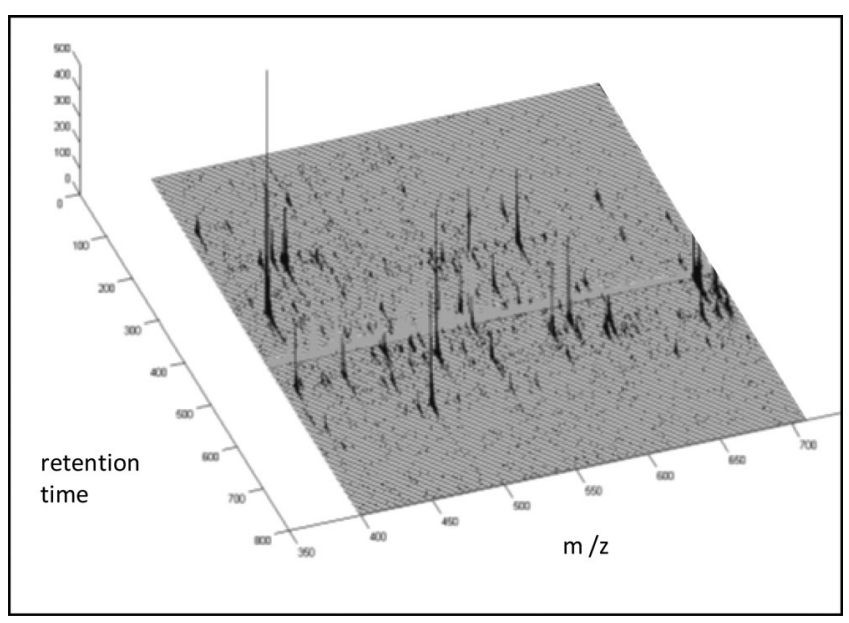

Fig. 6. Example of an LC-MS map: spectra obtained coupling MS (m/z domain) with LC (retention time domain).

peptide mass fingerprinting or double-stage spectra for tandem MS implementations) which require adequate computational techniques, also exploiting signal processing methods [45], which are in continuous evolution, to recover the protein content. A Human Proteomics Organization project, through the effort of an international consortium, has led to the identification, by means of MS-based proteomics, of 3020 proteins annotated as involved in cardiovascular functions; a subset of them (7\%) represents a collection of potential marker for $\mathrm{HF}$ and cardiac tissue remodeling [46], [47].

The protein expression profiling, performed through shotgun proteomics [tandem MS coupled with liquid chromatography (LC), see an example of LC-MS map in Fig. 6.], of a mouse model of DCM, was proposed by Isserlin et al. [48] comparing cardiac tissue of wild type and transgenic mice at three different times of disease progression [early-stage $(8 \mathrm{wk})$, midstage (16 wk), and end-stage ( $24 \mathrm{wk})]$. The time course experiment allowed to identify many proteins whose expression was dysregulated with HF progression: apoptosis and the MAPK (mitogen-activated protein kinase) cascade were the most significant perturbed pathways.

An interesting study based on 2-DE followed by LC-MS/MS identification, comparing left ventricular tissue lysates of failing and nonfailing human hearts, showed a specific pattern in membrane microdomains for failing hearts [49]; in Fig. 7, the reference gel image is reported along with the indication of differentially expressed spots.

A further complement to proteomic strategies is represented by metabolomics which investigates the presence of metabolites as fingerprint of the reactions actually occurring in the system. Also at this level of the information flow, there are evidences about the chance to identify novel biomarkers for HF. In Fig. 8, two examples of NMR spectra from plasma samples are reported, one for an HF patient and one for a control subject along with the exit of OPLS-DA, which displays the level of discrimination between affected and healthy subjects; the variable importance can then provide the indication about the more discriminant metabolites [50].

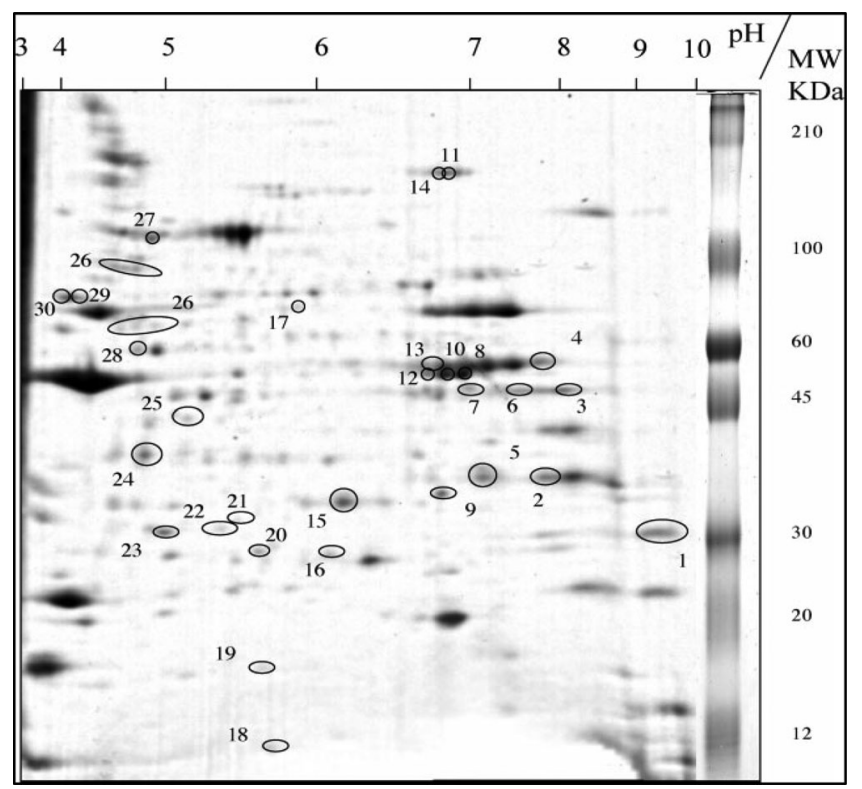

Fig. 7. Analysis, through 2-D gels followed by LC-MS/MS identification, of membrane microdomains isolated form left ventricular tissue of failing and nonfailing hearts. Differentially expressed spots are evidenced (from Banfi et al. 2006, reprinted with permission of Proetomics).

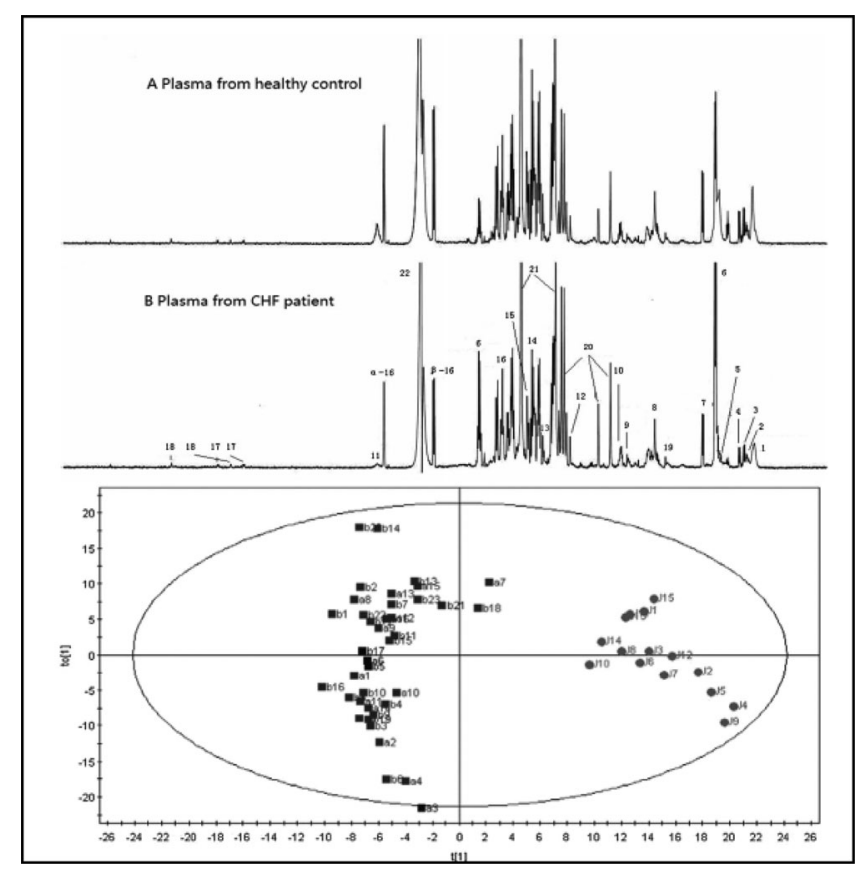

Fig. 8. Examples of NMR spectra are reported for plasma samples of a healthy control and an HF subject; informativeness of metabolomic spectra assessed through application of OPLS-DA to the collection of samples: score plots show a clear discrimination of healthy (circles) and diseased subjects (squares) (from Wang et al., 2013, reprinted with permission of Molecular Biosystems).

\section{HEART RATE VARIABILITY (HRV) AND HF}

As concerns phenotype assessed at the system level, HRV is a noninvasive quantitative marker of autonomic activity [51], which is derived from the interbeats series in the ECG (RR series). Interestingly, the regulations of the two main branches of the autonomic nervous system are reflected differently 

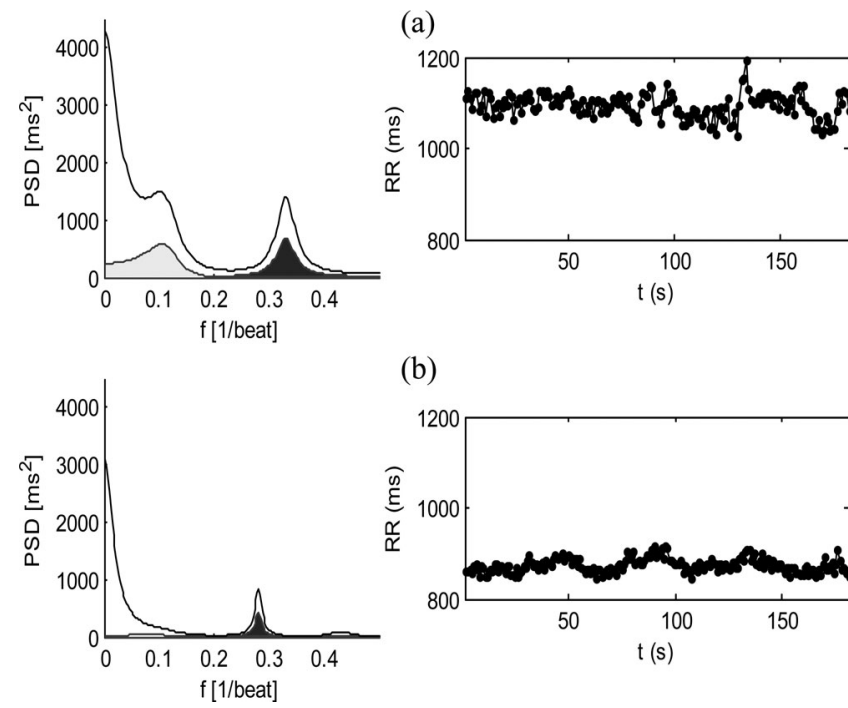

(b)

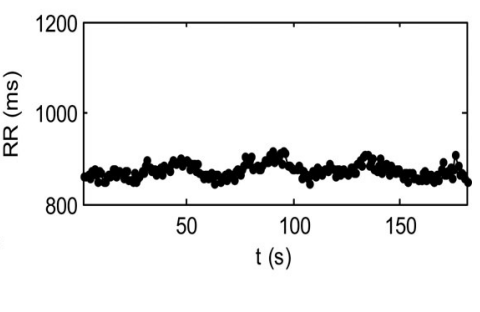

Fig. 9. HRV of a normal (panel a) and HF patient (b). The RR series (right) clearly evidences an increased heart rate and a reduced variability. The power spectral density (left) permits a finer analysis: HRV reduction is more pronounced in the low frequency range (LF) for this HF patient.

in the RR series [52]. The efferent vagal activity is a major contributor to oscillations having period of about 3-8 beats (the so-called high-frequency range, HF), while sympathetic modulation acts on longer time scales of about 10-30 beats (the low-frequency range, LF). A quantitative assessment through HRV analysis proved immediately effective [53]-[55] and a general reduction of HRV was found in HF patients, in apparent contradiction with the increased concentration of norepinephrine in plasma (a measure of sympathetic activation) reported. Possibly, overexpression of tumor necrosis factor and its receptors, which is typical of HF patients, could lead to a loss of adrenergic responsiveness and a subsequent HRV reduction [56].

Of the several traditional time and frequency methods developed to study HRV [51], many are linked to all-cause mortality (mostly pump failure) in HF patients, even when corrections for other clinical factors are included. In particular, SDNN (the standard deviation of all normal RR intervals [51]) and SDANN (the standard deviation of the averages of normal RR intervals in all 5-min segments of the entire recording [51]), which quantify global HRV variability, and the power in the ultra- and very low frequency band (oscillations with frequency smaller than $0.04 \mathrm{~Hz}$ ) were found to be independent predictor of mortality [57]. On the contrary, measures describing diminished vagal modulation only, like the power in the high-frequency range, pNN50 (the number of pairs of adjacent normal RR intervals differing by more than $50 \mathrm{~ms}$ in the entire recording, divided by the total number of normal RR intervals [51]) or RMSSD (the square root of the mean of the sum of the squares of differences between adjacent normal RR intervals [51]), were generally found to bring no additional information.

More interestingly, while an increased sympathetic activity would be expected to produce a relative predominance of LF os- cillations, both increased and reduced LF power were found to be associated with an increased risk of cardiac death. However, only a reduced LF power, derived from short-term measures, was consistently found to be an independent predictor of sudden cardiac death in HF patients. In particular, the predictive power was remarkable at night [58] or during controlled breathing [59], thus removing the potential confounding role of abnormal breathing patterns in the same frequency band. Therefore, despite a significant sympathoexcitation, in HF patients HRV variability is reduced, with low LF power (see Fig. 9), possibly due either to reduced responsiveness to chronic sympathetic overactivity [59] or, to a parasympathetic withdrawal.

While LF content in controlled breathing conditions might be the best contribution offered by traditional methods of HRV analysis to sudden death risk stratification, more complex signal processing approaches led to further advances. Such techniques are often termed "nonlinear" either to distinguish them from "linear" spectral analysis, but also as they drew largely from nonlinear dynamical systems theory and nonstationary stochastic processes analysis. Metrics influenced by variability's changes over long time scales proved to be substantially overlapping with clinical and functional risk factors, or with traditional indexes [58], in the prediction of all-cause mortality [60]. On the contrary short-term HRV nonlinear indexes indeed added prognostic information [57]. In particular, the short-term scaling exponent, obtained from detrended fluctuation analysis, was shown to be an independent predictor of cardiac mortality [61], more effective than traditional parameters. Also Poincaré (recurrence) plot analysis contributed in providing a marker of increased risk of both all-cause and sudden death which was independent from norepinephrine plasma concentration [62]. However, its computation was based on a qualitative visual evaluation of the Poincare plot, and further quantitative analysis needs to be performed. Finally, heart rate turbulence, a nonlinear metric of baroreflex sensitivity reflecting the severity of HF [63], was also shown to be an independent predictor of mortality in HF patients [64].

\section{CONCLUSION}

The huge amount of information provided by new highthroughput technologies at different scales requires the development of adequate analytical approaches to effectively exploit the availability of ever more complex "omics" data. Appropriate computational methods are essential both for the lowlevel analysis, to correctly process raw data, and for data mining and modeling. HF can be investigated across different levels of information from molecular profiling, disentangling the networks of key functional elements, to clinical phenotype, assessed with proper indexes at the cardiovascular and systemic level.

The integration of information from different ontologies is essential to make sense of complexity. More holistic models reconciling molecular biology with physiology in a systems biology perspective could really improve HF diagnosis and therapeutic opportunities. 


\section{REFERENCES}

[1] C.-C. Liew and V. J. Dzau, "Molecular genetics and genomics of heart failure," Nat. Rev. Genet., vol. 5, no. 11, pp. 811-825, Nov. 2004

[2] A. Mosterd and A. W. Hoes, "Clinical epidemiology of heart failure," Heart, vol. 93, no. 9, pp. 1137-1146, Sep. 2007.

[3] E. E. Creemers, A. A. Wilde, and Y. M. Pinto, "Heart failure: Advances through genomics," Nat. Rev. Genet., vol. 12, pp. 357-362, 2011.

[4] D. N. Tziakas, G. K. Chalikias and D. I. Xatseras, "Neurohormonal hypothesis in heart failure," Hellenic J. Cardiol., vol. 44, pp. 195-205, 2003.

[5] D. L. Mann and M. R. Bristow, "Mechanisms and models in heart failure: The biomechanical model and beyond," Circulation, vol. 111, no. 21, pp. 2837-2849, May 2005.

[6] E. E. Creemers and Y. M. Pinto, "Molecular mechanisms that control interstitial fibrosis in the pressure-overloaded heart," Cardiovasc. Res., vol. 89, no. 2, pp. 265-272, Feb. 2011.

[7] J. O. Mudd and D. A. Kass, "Tackling heart failure in the twenty-first century," Nature, vol. 451, no. 7181, pp. 919-928, Feb. 2008.

[8] I. J. Benjamin and M. D. Schneider, "Learning from failure: Congestive heart failure in the postgenomic age," J. Clin. Invest., vol. 115, no. 3, pp. 495-499, 2005.

[9] H. Morita, J. Seidman, and C. E. Seidman, "Genetic causes of human heart failure," J. Clin. Invest., vol. 115, no. 3, pp. 518-526, 2005.

[10] E. Carniel, M. R. G. Taylor, G. Sinagra, A. Di Lenarda, L. Ku, P. R. Fain, M. M. Boucek, J. Cavanaugh, S. Miocic, D. Slavov, S. L. Graw, J. Feiger, X. Z. Zhu, D. Dao, D. A. Ferguson, M. R. Bristow, and L. Mestroni, "Alpha-myosin heavy chain: A sarcomeric gene associated with dilated and hypertrophic phenotypes of cardiomyopathy," Circulation, vol. 112, no. 1, pp. 54-59, Jul. 2005.

[11] P. A. van der Zwaag, "One mutation fits all: Phospholamban R14del causes both dilated cardiomyopathy and arrithmogenic right ventricular cardyomyopathy/dysplasia," Circulation, vol. 122, A17663, 2010.

[12] J. H. Phan, C. F. Quo, and M. D. Wang, "Cardiovascular genomics: A biomarker identification pipeline," IEEE Trans. Inf. Technol. Biomed., vol. 16, no. 5, pp. 809-822, Sep. 2012.

[13] J. Yang, C. S. Moravec, M. A. Sussman, N. R. Dipaola, D. Fu, L. Hawthorn, C. A. Mitchell, J. B. Young, G. S. Francis, M. Patrick, M. Bond, and H. O. Arrays, "Decreased SLIM1 expression and increased gelsolin expression in failing human hearts measured by," Circulation, vol. 19, pp. 3046-3052, 2000.

[14] J. D. Barrans, D. Stamatiou, and C.-C. Liew, "Construction of a human cardiovascular cDNA microarray: Portrait of the failing heart," Biochem. Biophys. Res. Commun., vol. 280, no. 4, pp. 964-969, 2001.

[15] F.-L. Tan, C. S. Moravec, J. Li, C. Apperson-Hansen, P. M. McCarthy, J. B. Young, and M. Bond, "The gene expression fingerprint of human heart failure," Proc. Natl. Acad. Sci. USA, vol. 99, no. 17, pp. 1138711392, Aug. 2002.

[16] F. E. Dewey, M. V. Perez, M. T. Wheeler, C. Watt, J. Spin, P. Langfelder, S. Horvath, S. Hannenhalli, T. P. Cappola, and E. A Ashley, "Gene coexpression network topology of cardiac development, hypertrophy, and failure," Circ. Cardiovasc. Genet., vol. 4, no. 1, pp. 26-35, Feb. 2011.

[17] J.-H. Lee, C. Gao, G. Peng, C. Greer, S. Ren, Y. Wang, and X. Xiao, "Analysis of transcriptome complexity through RNA sequencing in normal and failing murine hearts," Circ. Res., vol. 109, no. 12, pp. 1332-1341, Dec. 2011.

[18] K.-D. Min, M. Asakura, Y. Liao, K. Nakamaru, H. Okazaki, T. Takahashi, K. Fujimoto, S. Ito, A. Takahashi, H. Asanuma, S. Yamazaki, T. Minamino, S. Sanada, O. Seguchi, A. Nakano, Y. Ando, T. Otsuka, H. Furukawa, T. Isomura, S. Takashima, N. Mochizuki, and M. Kitakaze, "Identification of genes related to heart failure using global gene expression profiling of human failing myocardium," Biochem. Biophys. Res. Commun., vol. 393, no. 1, pp. 55-60, Feb. 2010.

[19] P. Vanburen, J. Ma, S. Chao, E. Mueller, D. J. Schneider, and C.-C. Liew, "Blood gene expression signatures associate with heart failure outcomes," Physiol. Genomics, vol. 43, no. 8, pp. 392-397, Apr. 2011

[20] F. Smih, F. Desmoulin, M. Berry, A. Turkieh, R. Harmancey, J. Iacovoni, C. Trouillet, C. Delmas, A. Pathak, O. Lairez, F. Koukoui, P. Massabuau, J. Ferrieres, M. Galinier, and P. Rouet, "Blood signature of pre-heart failure: A microarrays study," PLoS One, vol. 6, no. 6, p. e20414, Jan. 2011

[21] B. He, R. Baird, R. Butera, A. Datta, S. George, B. Hecht, A. Hero, G. Lazzi, R. C. Lee, J. Liang, M. Neuman, G. C. Y. Peng, E. J. Perreault, M. Ramasubramanian, M. D. Wang, J. Wikswo, G.-Z. Yang, and Y.-T. Zhang, "Grand challenges in interfacing engineering with life sci- ences and medicine," IEEE Trans. Biomed. Eng., vol. 60, no. 3, pp. 589598, Mar. 2013.

[22] N. Battich, T. Stoeger, and L. Pelkmans, "Image-based transcriptomics in thousands of single human cells at single-molecule resolution," Nat. Methods, vol. 10, no. 11, pp. 1127-1133, Nov. 2013.

[23] L. Ng, S. D. Pathak, C. Kuan, C. Lau, H. Dong, A. Sodt, C. Dang, B. Avants, P. Yushkevich, J. C. Gee, D. Haynor, E. Lein, A. Jones, and M. Hawrylycz, "Neuroinformatics for genome-wide 3D gene expression mapping in the mouse brain," IEEE /ACM Trans. Comput. Biol. Bioinform., vol. 4, no. 3, pp. 382-393, Jul.-Sep. 2007.

[24] O. Rübel, G. H. Weber, M.-Y. Huang, E. W. Bethel, M. D. Biggin, C. C. Fowlkes, C. L. Luengo Hendriks, S. V. E. Keränen, M. B. Eisen, D. W. Knowles, J. Malik, H. Hagen, and B. Hamann, "Integrating data clustering and visualization for the analysis of 3D gene expression data," IEEE /ACM Trans. Comput. Biol. Bioinform., vol. 7, no. 1, pp. 64-79, Jan.-Mar. 2008.

[25] G. W. Dorn, "The genomic architecture of sporadic heart failure," Circ. Res., vol. 108, no. 10, pp. 1270-1283, May 2011.

[26] G. Medicine and E. G. Nabel, "Genomics of cardiovascular disease," $J$. Am. Coll. Cardiol., vol. 21, pp. 2098-2109, 2011.

[27] M. P. Donahue, D. A Marchuk, and H. A Rockman, "Redefining heart failure: The utility of genomics," J. Am. Coll. Cardiol., vol. 48, no. 7, pp. 1289-1298, Oct. 2006.

[28] V. Divakaran and D. L. Mann, "The emerging role of microRNAs in cardiac remodeling and heart failure," Circ. Res., vol. 103, no. 10, pp. 1072 1083, Nov. 2008.

[29] E. van Rooij, L. B. Sutherland, N. Liu, A. H. Williams, J. McAnally, R. D. Gerard, J. A Richardson, and E. N. Olson, "A signature pattern of stress-responsive microRNAs that can evoke cardiac hypertrophy and heart failure," Proc. Natl. Acad. Sci. USA, vol. 103, no. 48, pp. 1825518260, Nov. 2006.

[30] R. L. Montgomery, T. G. Hullinger, H. M. Semus, B. A Dickinson, A. G. Seto, J. M. Lynch, C. Stack, P. A Latimer, E. N. Olson, and E. van Rooij, "Therapeutic inhibition of miR-208 a improves cardiac function and survival during heart failure," Circulation, vol. 124, no. 14, pp. $1537-$ 1547, Oct. 2011

[31] P. S. Mitchell, R. K. Parkin, E. M. Kroh, B. R. Fritz, S. K. Wyman, E. L. Pogosova-Agadjanyan, A. Peterson, J. Noteboom, K. C. O'Briant, A. Allen, D. W. Lin, N. Urban, C. W. Drescher, B. S. Knudsen, D. L. Stirewalt, R. Gentleman, R. L. Vessella, P. S. Nelson, D. B. Martin and M. Tewari, "Circulating microRNAs as stable blood-based markers for cancer detection," Proc. Natl. Acad. Sci. USA, vol. 105, no. 30 pp. 10513-10518, Jul. 2008.

[32] G. Condorelli, M. V. G. Latronico, and G. W. Dorn, "microRNAs in hear disease: Putative novel therapeutic targets?" Eur. Heart J., vol. 31, no. 6 , pp. 649-658, Mar. 2010

[33] I. Elzenaar, Y. M. Pinto, and R. J. van Oort, "MicroRNAs in heart failure: New targets in disease management," Clin. Pharmacol. Ther, vol. 94 no. 4, pp. 480-489, 2013.

[34] A. J. Tijsen, E. E. Creemers, P. D. Moerland, L. J. de Windt, A. C. van der Wal, W. E. Kok, and Y. M. Pinto, "MiR423-5p as a circulating biomarker for heart failure," Circ. Res., vol. 106, no. 6, pp. 1035-1039, Apr. 2010.

[35] Y. Goren, M. Kushnir, B. Zafrir, S. Tabak, B. S. Lewis, and O. Amir "Serum levels of microRNAs in patients with heart failure," Eur. J. Heart Fail., vol. 14, no. 2, pp. 147-154, Feb. 2012.

[36] R. Papait, P. Kunderfranco, G. G. Stirparo, M. V. G. Latronico, and G. Condorelli, "Long noncoding RNA: A new player of heart failure?" $J$ Cardiovasc. Transl. Res., vol. 6, pp. 786-883, 2013.

[37] C. A. Klattenhoff, J. C. Scheuermann, L. E. Surface, R. K. Bradley, P. A. Fields, M. L. Steinhauser, H. Ding, V. L. Butty, L. Torrey, S. Haas, R. Abo, M. Tabebordbar, R. T. Lee, C. B. Burge, and L. A. Boyer, "Braveheart, a long noncoding RNA required for cardiovascular lineage commitment," Cell, vol. 152, no. 3, pp. 570-583, Jan. 2013.

[38] D. Li, G. Chen, J. Yang, X. Fan, Y. Gong, G. Xu, Q. Cui, and B. Geng, "Transcriptome analysis reveals distinct patterns of long noncoding RNAs in heart and plasma of mice with heart failure," PLoS One, vol. 8, no. 10, p. e77938, Jan. 2013.

[39] L. Korostowski, N. Sedlak, and N. Engel, "The kenq1ot1 long non-coding RNA affects chromatin conformation and expression of kenq1, but does not regulate its imprinting in the developing heart," PLoS Genet., vol. 8, no. 9, p. e1002956, Sep. 2012.

[40] M. Movassagh, M.-K. Choy, M. Goddard, M. R. Bennett, T. A. Down, and R. S.-Y. Foo, "Differential DNA methylation correlates with differential expression of angiogenic factors in human heart failure," PLoS One, vol. 5 , no. 1, p. e8564, Jan. 2010. 
[41] M. Movassagh, M.-K. Choy, D. A. Knowles, L. Cordeddu, S. Haider, T. Down, L. Siggens, A. Vujic, I. Simeoni, C. Penkett, M. Goddard, P. Lio, M. R. Bennett, and R. S.-Y. Foo, "Distinct epigenomic features in end-stage failing human hearts," Circulation, vol. 124, no. 22, pp. 24112422, Nov. 2011.

[42] B. Duygu, E. M. Poels, and P. A. da Costa Martins, "Genetics and epigenetics of arrhythmia and heart failure," Front. Genet., vol. 4, no. 219, pp. 1-15, 2013.

[43] J. Haas, K. S. Frese, Y. J. Park, A. Keller, B. Vogel, A. M. Lindroth, D. Weichenhan, J. Franke, S. Fischer, A. Bauer, S. Marquart, F. SedaghatHamedani, E. Kayvanpour, D. Köhler, N. M. Wolf, S. Hassel, R. Nietsch, T. Wieland, P. Ehlermann, J.-H. Schultz, A. Dösch, D. Mereles, S. Hardt, J. Backs, J. D. Hoheisel, C. Plass, H. A. Katus, and B. Meder, "Alterations in cardiac DNA methylation in human dilated cardiomyopathy," $E M B O$ Mol. Med., vol. 5, no. 3, pp. 413-429, Mar. 2013.

[44] L. Pattini, S. Mazzara, A. Conti, S. Iannaccone, S. Cerutti, and M. Alessio, "An integrated strategy in two-dimensional electrophoresis analysis able to identify discriminants between different clinical conditions," Exp. Biol. Med. (Maywood), vol. 233, no. 4, pp. 483-491, Apr. 2008.

[45] S. Cappadona, F. Levander, M. Jansson, P. James, S. Cerutti, and L. Pattini, "Wavelet-based method for noise characterization and rejection in highperformance liquid chromatography coupled to mass spectrometry," Anal. Chem., vol. 80, no. 13, pp. 4960-4968, Jul. 2008.

[46] B. T. Berhane, C. Zong, D. A. Liem, A. Huang, S. Le, R. D. Edmondson, R. C. Jones, X. Qiao, J. P. Whitelegge, P. Ping, and T. M. Vondriska, "Cardiovascular-related proteins identified in human plasma by the HUPO plasma proteome project pilot phase," Proteomics, vol. 5, no. 13, pp. 3520 3530, Aug. 2005.

[47] E. Dubois, M. Fertin, J. Burdese, P. Amouyel, C. Bauters, and F. Pinet, "Cardiovascular proteomics: Translational studies to develop novel biomarkers in heart failure and left ventricular remodeling," Proteomics. Clin. Appl., vol. 5, no. 1/2, pp. 57-66, Mar. 2011.

[48] R. Isserlin, D. Merico, R. Alikhani-Koupaei, A. Gramolini, G. D. Bader, and A. Emili, "Pathway analysis of dilated cardiomyopathy using global proteomic profiling and enrichment maps," Proteomics, vol. 10, no. 6, pp. 1316-1327, Mar. 2010.

[49] C. Banfi, M. Brioschi, R. Wait, S. Begum, E. Gianazza, P. Fratto, G. Polvani, E. Vitali, A. Parolari, L. Mussoni, and E. Tremoli, "Proteomic analysis of membrane microdomains derived from both failing and non-failing human hearts," Proteomics, vol. 6, no. 6, pp. 1976-1988, Mar. 2006.

[50] J. Wang, Z. Li, J. Chen, H. Zhao, L. Luo, C. Chen, X. Xu, W. Zhang, K. Gao, B. Li, J. Zhang, and W. Wang, "Metabolomic identification of diagnostic plasma biomarkers in humans with chronic heart failure," Mol. Biosyst., vol. 9, no. 11, pp. 2618-2626, Oct. 2013.

[51] Task Force of the European Society of Cardiology and the North American Society of Pacing and Electrophysiology, "Heart rate variability standards of measurement, physiological interpretation, and clinical use," Circulation, vol. 93, no. 5, pp. 1043-1065, Jan. 1996.

[52] M. Pagani, F. Lombardi, S. Guzzetti, O. Rimoldi, R. Furlan, P. Pizzinelli, G. Sandrone, G. Malfatto, S. Dell'Orto, and E. Piccaluga, "Power spectral analysis of heart rate and arterial pressure variabilities as a marker of sympatho-vagal interaction in man and conscious dog," Circ. Res., vol. 59, no. 2, pp. 178-193, Aug. 1986.

[53] G. Pardi, E. Ferrazzi, I. Cetin, S. Rampello, G. Baselli, S. Cerutti, and S. Civardi, "The clinical relevance of the abdominal fetal electrocardiogram," J. Perinat. Med., vol. 14, no. 6, pp. 371-377, 1986.

[54] J. P. Saul, Y. Arai, R. D. Berger, L. S. Lilly, W. S. Colucci, and R. J. Cohen, "Assessment of autonomic regulation in chronic congestive heart failure by heart rate spectral analysis," Am. J. Cardiol., vol. 61, no. 15, pp. 1292 1299, Jun. 1988.

[55] P. van de Borne, N. Montano, M. Pagani, R. Oren, and V. K. Somers, "Absence of low-frequency variability of sympathetic nerve activity in severe heart failure," Circulation, vol. 95, no. 6, pp. 1449-1454, Mar. 1997.

[56] H. A. Malave, A. A. Taylor, J. Nattama, A. Deswal, and D. L. Mann, "Circulating levels of tumor necrosis factor correlate with indexes of depressed heart rate variability: A study in patients with mild-to-moderate heart failure," Chest, vol. 123, no. 3, pp. 716-724, Mar. 2003.

[57] G. R. H. Sandercock and D. A. Brodie, "The role of heart rate variability in prognosis for different modes of death in chronic heart failure," Pacing Clin. Electrophysiol., vol. 29, no. 8, pp. 892-904, 2006

[58] S. Guzzetti, M. T. La Rovere, G. D. Pinna, R. Maestri, E. Borroni, A. Porta, A. Mortara, and A. Malliani, "Different spectral components of $24 \mathrm{~h}$ heart rate variability are related to different modes of death in chronic heart failure," Eur. Heart J., vol. 26, no. 4, pp. 357-362, Jan. 2005.

[59] M. T. La Rovere, G. D. Pinna, R. Maestri, A. Mortara, S. Capomolla, O. Febo, R. Ferrari, M. Franchini, M. Gnemmi, C. Opasich, P. G. Riccardi, E. Traversi, and F. Cobelli, "Short-term heart rate variability strongly predicts sudden cardiac death in chronic heart failure patients," Circulation, vol. 107, no. 4, pp. 565-570, Apr. 2003.

[60] R. Maestri, G. D. Pinna, A. Accardo, P. Allegrini, R. Balocchi, G. D’addio, M. Ferrario, D. Menicucci, A. Porta, R. Sassi, M. G. Signorini, M. T. La Rovere, and S. Cerutti, "Nonlinear indices of heart rate variability in chronic heart failure patients: Redundancy and comparative clinical value," J. Cardiovasc. Electrophysiol., vol. 18, no. 4, pp. 425-433, 2007.

[61] T. H. Mäkikallio, H. V Huikuri, U. Hintze, J. Videbæk, R. D. Mitrani, A. Castellanos, R. J. Myerburg, and M. Møller, "Fractal analysis and timeand frequency-domain measures of heart rate variability as predictors of mortality in patients with heart failure," Am. J. Cardiol., vol. 87, no. 2, pp. 178-182, Jan. 2001.

[62] J. Brouwer, D. J. van Veldhuisen, A. J. Man In't Veld, J. Haaksma, W. A. Dijk, K. R. Visser, F. Boomsma, P. H. J. M. Dunselman, and K. I. Lie, "Prognostic value of heart rate variability during long-term follow-up in patients with mild to moderate heart failure," J. Am. Coll. Cardiol., vol. 28, no. 5, pp. 1183-1189, Nov. 1996.

[63] I. Cygankiewicz, W. Zareba, R. Vazquez, M. Vallverdu, J. Cino, J. Cinca, J. Almendral, J. R. Gonzalez Juanatey, C. Macaya, M. Valdes, P. Caminal, and A. Bayes de Luna, "Relation of heart rate turbulence to severity of heart failure," Am. J. Cardiol., vol. 98, no. 12, pp. 1635-1640, Dec. 2006.

[64] I. Cygankiewicz, W. Zareba, R. Vazquez, A. Bayes-Genis, D. Pascual, C. Macaya, J. Almendral, M. Fiol, A. Bardaji, J. R. Gonzalez-Juanatey, V. Nieto, M. Valdes, J. Cinca, and A. B. de Luna, "Risk stratification of mortality in patients with heart failure and left ventricular ejection fraction >35\%," Am. J. Cardiol., vol. 103, no. 7, pp. 1003-1010, Apr. 2009.

[65] N. L. Smith, J. F. Felix, A. C. Morrison, S. Demissie, N. L. Glazer, L. R. Loehr, L. A. Cupples, A. Dehghan, T. Lumley, W. D. Rosamond, W. Lieb, F. Rivadeneira, J. C. Bis, A. R. Folsom, E. Benjamin, Y. S. Aulchenko, T. Haritunians, D. Couper, J. Murabito, Y. A. Wang, B. H. Stricker, J. S. Gottdiener, P. P. Chang, T. J. Wang, K. M. Rice, A. Hofman, S. R. Heckbert, E. R. Fox, C. J. O’Donnell, A. G. Uitterlinden, J. I. Rotter, J. T. Willerson, D. Levy, C. M. van Duijn, B. M. Psaty, J. C. M. Witteman, E. Boerwinkle, and R. S. Vasan, "Association of genome-wide variation with the risk of incident heart failure in adults of european and african ancestry: A prospective meta-analysis from the cohorts for heart and aging research in genomic epidemiology (CHARGE) consortium," Circ. Cardiovasc. Genet., vol. 3, no. 3, pp. 256-266, Jun. 2010 .

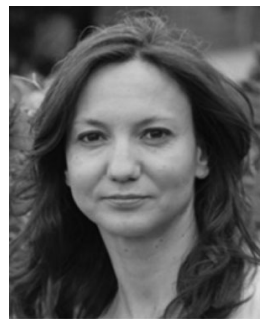

Linda Pattini received the Laurea (B.Sc. and M.Sc.) and the Pd.D. degrees in biomedical engineering from the Politecnico di Milano, Italy, in 1999 and 2003, respectively.

Nowadays, she is an Assistant Professor in the Department of Electronics, Information and Bioengineering of the same university where she teaches bioinformatics (Master degree in biomedical engineering) and she is an Adjunct Professor at the University Vita-Salute San Raffaele (Bachelor degree in medical and pharmaceutical biotechnology). Her research activity concerns the development and the application of methods of processing for integrative bioinformatics and functional genomics. Specifically, her interests include the study of the signals involved in the functional specification of genomic sequences, gene expression data analysis for the study and the modeling of interactions in a systems biology perspective, computational approaches for data processing in the large-scale proteomics workflow and statistical genetics. 


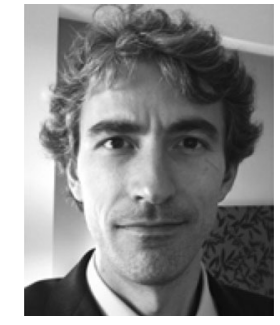

Roberto Sassi (M'06-SM'12) received the Laurea degree (B.Sc. and M.Sc.) in electronic engineering, and the $\mathrm{Ph} . \mathrm{D}$. degree in biomedical engineering, both from Politecnico di Milano, Italy, in 1996 and 2001, respectively.

After graduation, he worked as a Postdoctoral Researcher at the University of California, Santa Cruz, USA, in mathematical modeling of non-Newtonian fluids and at Politecnico di Milano, in cooperation with Ela Medical, Paris, France, on ECG signals and atrial fibrillation. He is currently an Assistant Professor ("Ricercatore Confermato") at the Università degli Studi di Milano, Italy. He taught courses of digital signal and image processing, statistics and programming. His research interests include biomedical signal processing, linear and nonlinear time series analysis, biometrics, with special emphasis on privacy protection issues, and applied mathematics. He is author of several papers in international scientific journals and conferences and he filed a patent on biometrics encryption.

Dr. Sassi is member of the AEIT and a 1999 WHOI-GFD fellow.

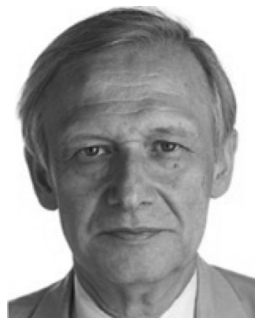

Sergio Cerutti (M'81-SM'97-F'03) received the Laurea degree (B.Sc. and M.Sc.) in electronic engineering, in 1971.

Currently, he is a Professor in biomedical engineering (BME) at the Department of Electronics, Information and Bioengineering, Politecnico di Milano, Italy. In 2000-2006, he has been the Chairman of the Department of Bioengineering, and in 2010 2012 the Chairman of BME Programs. His research interests include mainly in biomedical signal processing, neurosciences, and cardiovascular modeling. In his research activity, he has put emphasis on the integration of information a different modalities, at different sources, and at different scales in various physiological systems. Since 1983, he has taught a course at graduate and doc levels on biomedical signal processing and modeling at Engineering Faculties (Milano and Roma) as well as at Specialisation Schools of Medical Faculties. He is the Author of more than 500 international scientific contributions (more than 250 on indexed scientific journals).

Prof. Cerutti has been Elected Member of IEEE-EMBS AdCom (Region 8) in 1993-1996 and 2011-2013. He is actually Fellow Member of the EAMBES, the AIMBE and an Associate Editor of the IEEE TRANSACTION ON BIOMEDICAL ENGINEERING. He is a member of the Steering Committee of the IEEE-EMBS Summer School on Biomedical Signal Processing. He has been Visiting Professor at Harvard-MIT Division Health Science and Technology, Boston, USA, for an overall period of one year as well as for a period of four months at IST—Department of Physics, Lisbon, Portugal. In 2009, he received the IEEEEMBS Academic Career Achievement Award. 